\title{
The FFC-Cambridge Process for Titanium Metal Winning
}

\author{
Carsten Schwandt ${ }^{1, a}$, Greg R. Doughty ${ }^{2, b}$, Derek J. Fray ${ }^{1, c}$ \\ ${ }^{1}$ Department of Materials Science and Metallurgy, University of Cambridge, Pembroke Street, \\ Cambridge, CB2 3QZ, United Kingdom \\ ${ }^{2}$ Inertius Ltd., Advanced Manufacturing Technology Centre, Advanced Manufacturing Park, Brunel \\ Way, Rotherham, S60 5WG, United Kingdom \\ formerly: British Titanium plc, 55 Clifton Road, Cambridge, CB1 7EF, United Kingdom \\ a cs254@cam.ac.uk, b greg.doughty@inertius.net, c djf25@cam.ac.uk
}

Keywords: FFC-Cambridge process, Electrochemical reduction, Electro-deoxidation, Calcium chloride, Calcium oxide, Titanium dioxide, Titanium, Scale-up, Pilot plant.

\begin{abstract}
The FFC-Cambridge process is a molten salt electrochemical deoxidation method that was invented at the Department of Materials Science and Metallurgy of the University of Cambridge one decade ago. It is a generic technology that allows the direct conversion of metal oxides into the corresponding metals through cathodic polarisation of the oxide in a molten salt electrolyte based on calcium chloride. The process is rather universal in its applicability, and numerous studies on metals, semimetals, alloys and intermetallics have since been performed at the place of its invention and worldwide. The electro-winning of titanium metal is a particularly rewarding target because of the disadvantages of the existing extraction methods. This article summarises the research work performed on the FFC-Cambridge process at the University of Cambridge and its industrial partners with a focus on the electro-winning of titanium metal from titanium dioxide. Topics addressed encompass the invention of the process, early proof-of-concept work, the identification of the reaction pathway, and the investigation and optimisation of the key process parameters. Also discussed are aspects of technology transfer and some of the development work undertaken to date.
\end{abstract}

\section{Background and Invention of the FFC-Cambridge Process}

It is well known that titanium picks up oxygen when exposed to an oxygen-containing environment at elevated temperatures. In addition to forming an oxide coating, titanium is able to dissolve substantial amounts of oxygen to form an oxygen-rich metallic layer, called the alpha case, which has to be removed as its properties are inferior compared with the bulk metal. Removal of the surface layer of an artefact is usually achieved by either dissolving it in a mixture of nitric and hydrofluoric acids or by grinding it away. In both cases, the dimensions of the component change, and there are disposal problems with the generated waste.

In an approach to remove oxygen from titanium without invoking a change in dimensions, it was proposed that in a calcium chloride melt it should be possible to expel the oxygen by making the artefact the cathode. The suggested cathode reaction was:

$$
\mathrm{O}(\text { in } \mathrm{Ti})+2 \mathrm{e}^{-}=\mathrm{O}^{2-}\left(\text { in } \mathrm{CaCl}_{2}\right)
$$

Upon release from the titanium cathode, the oxide ions dissolve into the molten salt electrolyte, and then diffuse to the anode where discharge takes place. In order for the reaction in Eq. 1 to occur, two criteria need to be fulfilled. One is that the removal of the dissolved oxygen is possible at electrode potentials that are less cathodic than that for calcium deposition from the molten salt. The other is that the molten salt is able to dissolve oxide ions. 
Laboratory experiments verified that it was indeed possible to deoxidise the surface of titanium samples with the proposed approach. Normally, the samples were exposed to the oxidising environment for a short time only but, in some cases, samples were exposed for many hours so that thick oxide coatings were formed. Rather surprisingly, these too were reduced by the electrochemical treatment. In an extension of Eq. 1, the suggested cathode reaction was:

$$
\mathrm{TiO}_{2}+4 \mathrm{e}^{-}=\mathrm{Ti}+2 \mathrm{O}^{2-}\left(\text { in } \mathrm{CaCl}_{2}\right)
$$

This finding led directly to the proposal that by making an oxide the cathode in a bath of a halide of a very electropositive element, the oxide would be reduced. This was proven to be the case, and a patent has been granted on this new generic electro-deoxidation method [1]. A series of studies was initiated to attempt to understand how an insulating oxide could be reduced to a metal with low residual oxygen content [2-4].

One of the driving forces for the subsequent research was to determine whether this novel process of electro-deoxidation was likely to be competitive with conventional metal production processes. The direct conversion of titanium dioxide to titanium metal was deemed a particularly rewarding target because of the inherent drawbacks of the existing technologies like the Kroll and the Hunter processes. Also the possibility of forming alloys directly from the corresponding oxide mixtures was considered an attractive goal $[5,6]$.

\section{Studies on the Electro-deoxidation of Titanium Dioxide at Laboratory Scale}

The overall cathode reaction in the reduction of $\mathrm{TiO}_{2}$ to $\mathrm{Ti}$ by way of the FFC-Cambridge process is the removal of oxygen from the solid oxide cathode, while the titanium remains therein. The overall cathode reaction is given in Eq. 2. However, already in the early studies, a number of observations were made that gave clear indication of the kinetic pathway of the cathode reaction being more complex than what the simple overall reaction would suggest. Most notably, it was consistently observed that calcium-containing compounds like calcium titanate, $\mathrm{CaTiO}_{3}$, and, calcium titanite, $\mathrm{CaTi}_{2} \mathrm{O}_{4}$, were present in the cathode partway through the reduction and that the cathode underwent a temporary mass gain.

\section{Electro-deoxidation experiments with a two-terminal cell, constant potential, and low CaO concentration}

The above observations prompted an in-depth investigation into the reaction pathway of the reduction of $\mathrm{TiO}_{2}$ to $\mathrm{Ti}$. The experiments in the first systematic study on $\mathrm{TiO}_{2}$ reduction $[7,8]$ were conducted by cathodically polarising $\mathrm{TiO}_{2}$ discs, of 4 to $16 \mathrm{~g}$ in mass and with $25-30 \%$ open porosity, against a graphite anode in a $\mathrm{CaCl}_{2}$ molten salt electrolyte at $900{ }^{\circ} \mathrm{C}$ under argon. Fig. 1 presents a schematic of the electrochemical cell, and Fig. 2 shows a photograph of a typical laboratory set-up. Applied potentials were between -2.5 and $-2.9 \mathrm{~V}$ and were maintained for different periods of time, ranging from $0.5-120 \mathrm{~h}$, before reduction was interrupted by withdrawing the sample from the electrolyte. Importantly, in this set of experiments the $\mathrm{CaO}$ concentration in the $\mathrm{CaCl}_{2}$ was low with values on the order of $0.2 \mathrm{~mol} \%$. The partially reduced samples were then subjected to a thorough examination using X-ray diffraction analysis, optical microscopy, scanning electron microscopy and energy-dispersive X-ray spectroscopy. The advantage of analysing partially reduced discs over, for instance, cyclic voltammograms from thin films, is that the former studies relate to conditions that would be applied in a scaled-up production process. 


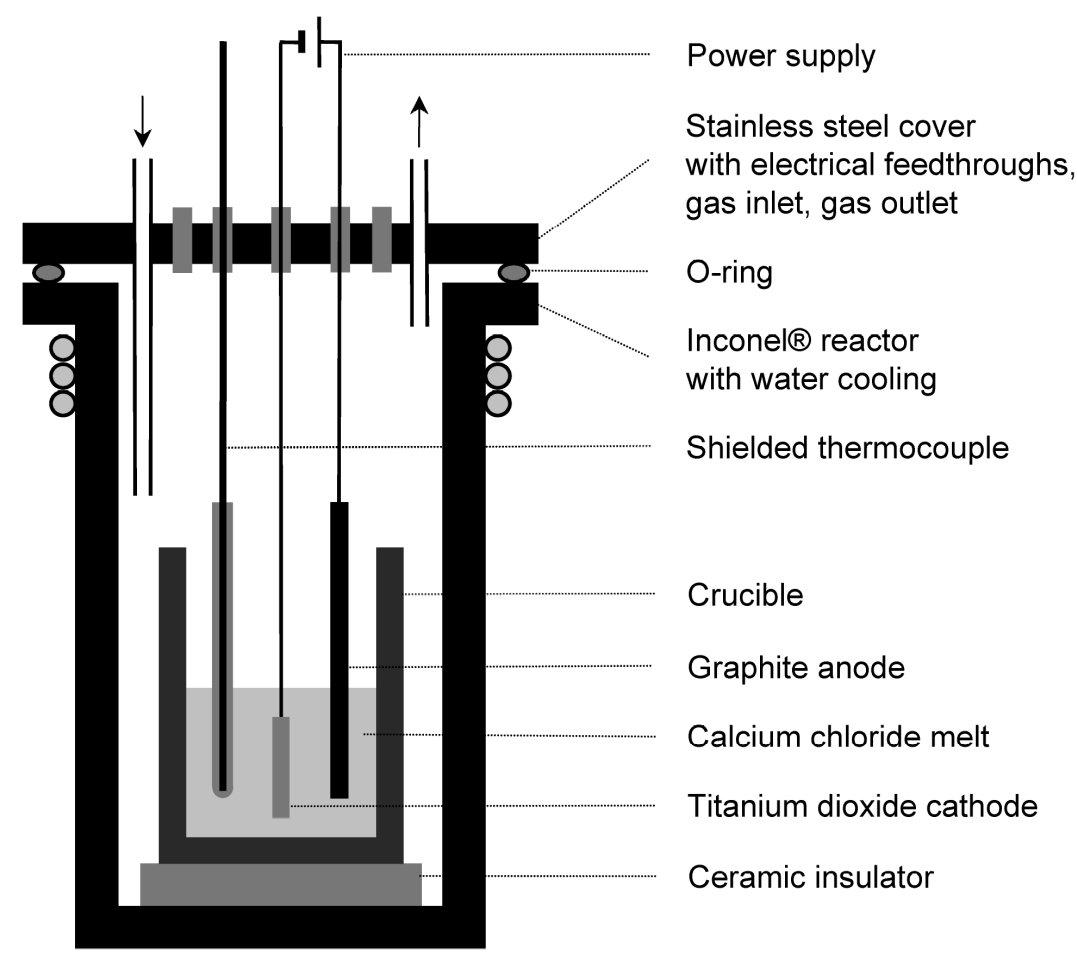

Fig. 1. Schematic of the electrochemical cell for electro-deoxidation experiments, showing the various components.

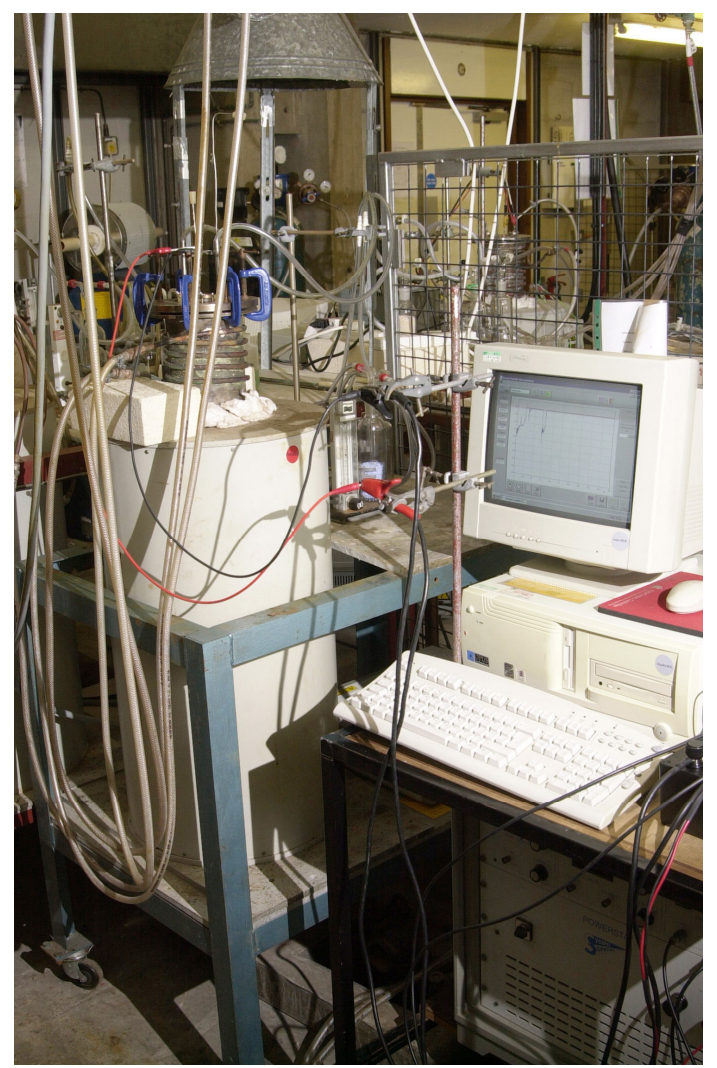

Fig. 2. Photograph of a typical laboratory set-up for electro-deoxidation experiments, showing metal retort, furnace, argon supply and electrochemical equipment. 
Fig. 3 shows the initial phase of a current versus time curve recorded during a reduction experiment of the above type. There is an initial current peak, which extends over $1 \mathrm{~h}$. This is followed by a current shoulder, which extends over a further $4 \mathrm{~h}$. Finally the current assumes a rather small value, which remains relatively constant throughout the remainder of the experiment and only changes markedly when varying the applied potential.

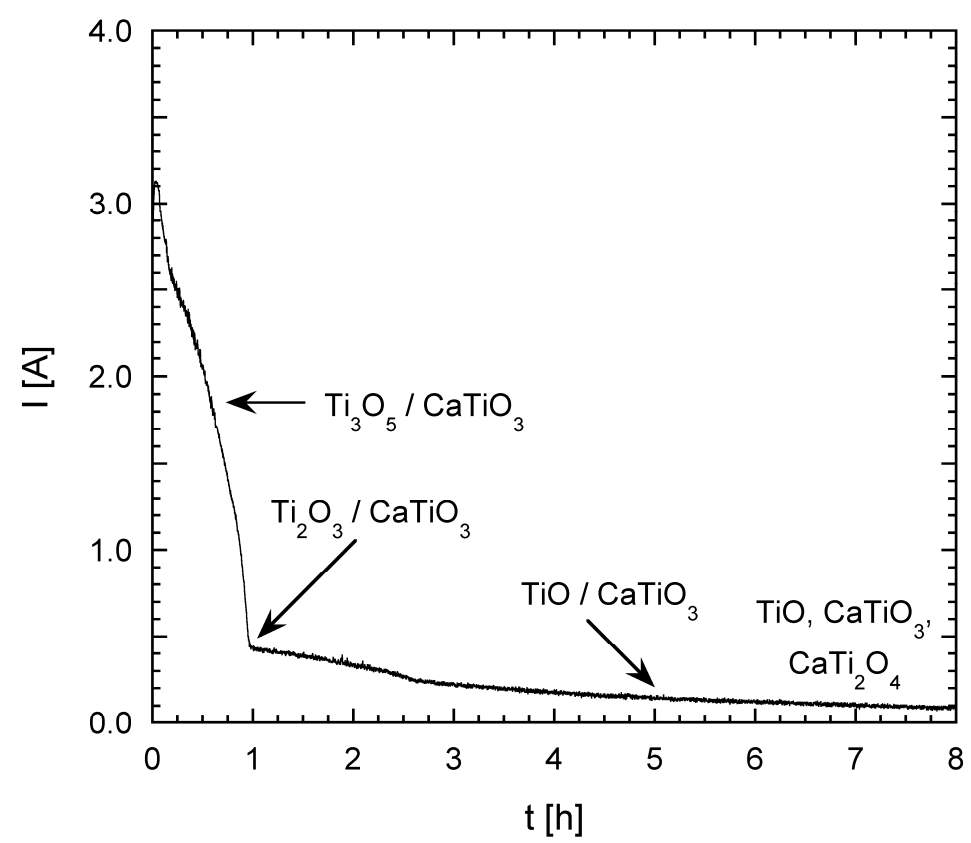

Fig. 3. Current versus time curve recorded during an electro-deoxidation experiment of $\mathrm{TiO}_{2}$ in a two-terminal cell; electrolyte: $\mathrm{CaCl}_{2}$; cathode: porous $\mathrm{TiO}_{2}$ disc of mass $8 \mathrm{~g}$; anode: graphite; total applied potential: $2.5 \mathrm{~V}$; temperature: $900^{\circ} \mathrm{C}$; atmosphere: dried argon.

It was concluded from Fig. 3 that the current during the initial peak would be too large to be sustained by oxide ions alone, since the $\mathrm{CaO}$ concentration in these experiments was low. This triggered the realisation that the first phase of the process is determined by the incorporation of calcium ions into the cathode. On the basis of information on phase composition, elemental composition and mass of the quenched samples as well as the amount of charge passed up to the point of terminating the experiment, the following sequence of cathodic reactions was derived:

$$
\begin{array}{ll}
5 \mathrm{TiO}_{2}+\mathrm{Ca}^{2+}+2 \mathrm{e}^{-}=\mathrm{Ti}_{4} \mathrm{O}_{7}+\mathrm{CaTiO}_{3}, & E^{0}=+1797 \mathrm{mV}, \\
4 \mathrm{Ti}_{4} \mathrm{O}_{7}+\mathrm{Ca}^{2+}+2 \mathrm{e}^{-}=5 \mathrm{Ti}_{3} \mathrm{O}_{5}+\mathrm{CaTiO}_{3}, & E^{0}=+1668 \mathrm{mV}, \\
3 \mathrm{Ti}_{3} \mathrm{O}_{5}+\mathrm{Ca}^{2+}+2 \mathrm{e}^{-}=4 \mathrm{Ti}_{2} \mathrm{O}_{3}+\mathrm{CaTiO}_{3}, & E^{0}=+1564 \mathrm{mV} .
\end{array}
$$

In these reactions, the $\mathrm{Ca}^{2+}$ ions originate from the electrolyte and the electrons are injected from the negative terminal. It should be noted that the $\mathrm{Ca}^{2+}$ ions remain in the oxidation state of +2 , and that no $\mathrm{Ca}$ metal is formed at any point in these reactions. The species to be reduced is the Ti ion. In the Ti-suboxide the Ti eventually reaches the oxidation state +3 , while in the $\mathrm{CaTiO}_{3}$ the Ti remains in its original oxidation state of +4 . The current peak is of a comparatively short duration, indicating that the formation of the mixtures of Ti-suboxides and $\mathrm{CaTiO}_{3}$ is kinetically facile. It was realised 
that all the transitions between $\mathrm{TiO}_{2}$ and $\mathrm{Ti}_{2} \mathrm{O}_{3}$ are fast because, as oxygen is removed, the type of oxygen coordination around the titanium remains intact, with the oxygen octahedra changing from corner-sharing to edge-sharing to face-sharing; nucleation and growth of the $\mathrm{CaTiO}_{3}$ also occur rapidly.

The reaction during the current shoulder was again found to involve the incorporation of $\mathrm{Ca}$ ions into the cathode. Based on the experimental results, and in extension of the sequence above, the following cathodic reaction was identified:

$$
2 \mathrm{Ti}_{2} \mathrm{O}_{3}+\mathrm{Ca}^{2+}+2 \mathrm{e}^{-}=3 \mathrm{TiO}+\mathrm{CaTiO}_{3}, \quad E^{0}=+1189 \mathrm{mV}
$$

The species to be reduced continues to be the $\mathrm{Ti}$ ion in the Ti-suboxides, which now reaches the oxidation state +2 . The current shoulder is of significantly longer duration than the preceding current peak, indicating that the transition from $\mathrm{Ti}_{2} \mathrm{O}_{3}$ to $\mathrm{TiO}$ is kinetically more demanding than the foregoing ones. This is because the formation of $\mathrm{TiO}$ from $\mathrm{Ti}_{2} \mathrm{O}_{3}$ cannot occur via a simple shearing mechanism but requires a complete and comparatively slow reorganisation in the oxygen sublattice.

In the next phase $\mathrm{CaTi}_{2} \mathrm{O}_{4}$ becomes the dominant compound in the cathode. $\mathrm{CaTi}_{2} \mathrm{O}_{4}$ forms in large quantities from the mixture of $\mathrm{TiO}$ and $\mathrm{CaTiO}_{3}$. The following reaction accounts for this observation:

$$
\mathrm{CaTiO}_{3}+\mathrm{TiO}=\mathrm{CaTi}_{2} \mathrm{O}_{4}
$$

This reaction is entirely chemical in nature. $\mathrm{Ti}$ of oxidation state +2 in the $\mathrm{TiO}$ and $\mathrm{Ti}$ of oxidation state +4 in the $\mathrm{CaTiO}_{3}$ comproportionate, forming $\mathrm{CaTi}_{2} \mathrm{O}_{4}$ with $\mathrm{Ti}$ in the oxidation state +3 , thus leaving the average oxidation state of the Ti unchanged. Evidently the Gibbs free energy of formation of $\mathrm{CaTi}_{2} \mathrm{O}_{4}$ must be lower than the sum of those of $\mathrm{TiO}$ and $\mathrm{CaTiO}_{3}$, which allows this reaction to lower the energy of the system.

The subsequent phase is the breakdown of the $\mathrm{CaTi}_{2} \mathrm{O}_{4}$ to $\mathrm{TiO}$. This is expressed by the following cathodic reaction:

$$
\mathrm{CaTi}_{2} \mathrm{O}_{4}+2 \mathrm{e}^{-}=2 \mathrm{TiO}+\mathrm{Ca}^{2+}+2 \mathrm{O}^{2-}, \quad E^{0}<+416 \mathrm{mV} .
$$

This reaction step is critical for several reasons. Firstly, calcium incorporation into the cathode is no longer possible, and therefore the reduction must now involve the removal of oxygen, which gives rise to the formation of $\mathrm{TiO}$ with $\mathrm{Ti}$ in the oxidation state +2 . Secondly, no compounds exist that contain $\mathrm{Ca}^{2+}$ ions as well as $\mathrm{Ti}$ in the oxidation state +2 and $\mathrm{O}^{2-}$ ions, and so the previously incorporated $\mathrm{Ca}$ must now be expelled from the cathode. Effectively this means that $\mathrm{CaO}$ is released from the cathode and if this occurs too quickly, there is a risk of locally saturating the $\mathrm{CaCl}_{2}$ with $\mathrm{CaO}$ and hence stalling the process. Thirdly, the microstructural changes associated with this reaction step are dramatic, as will be discussed briefly below. Of particular note is the observation that, under the given conditions, the reduction of the $\mathrm{CaTi}_{2} \mathrm{O}_{4}$ progresses sluggishly. This was attributed to the low $\mathrm{CaO}$ concentration in the $\mathrm{CaCl}_{2}$ which slows oxide ion transport across the electrolyte.

In the final phase the $\mathrm{TiO}$ is reduced to $\mathrm{Ti}$ with residual $\mathrm{O}$ dissolved in it. This is denoted by the following cathodic reaction:

$$
\mathrm{TiO}+2(1-\delta) \mathrm{e}^{-}=\mathrm{Ti}[\mathrm{O}]_{\delta}+(1-\delta) \mathrm{O}^{2-}, \quad \quad E^{0}=+173 \mathrm{mV}
$$

This reaction provides the final product. It was found in the experiments that $\mathrm{Ti}$ with residual oxygen contents on the order of 3000 ppm by mass could be prepared, albeit after typical polarisation times of around $100 \mathrm{~h}$ or more. 
(a)

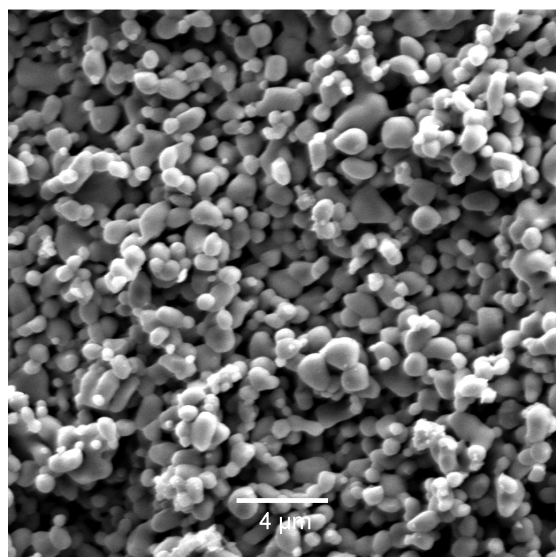

(b)

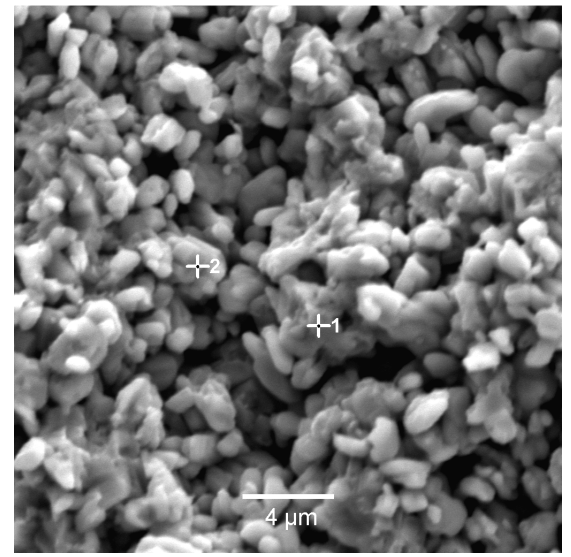

(c)

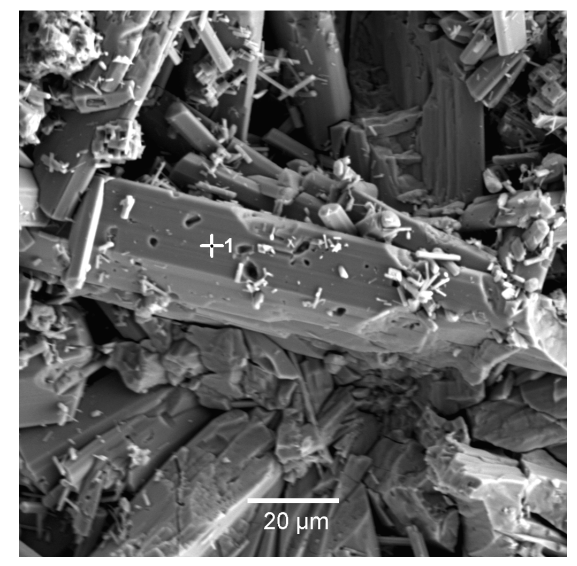

(d)

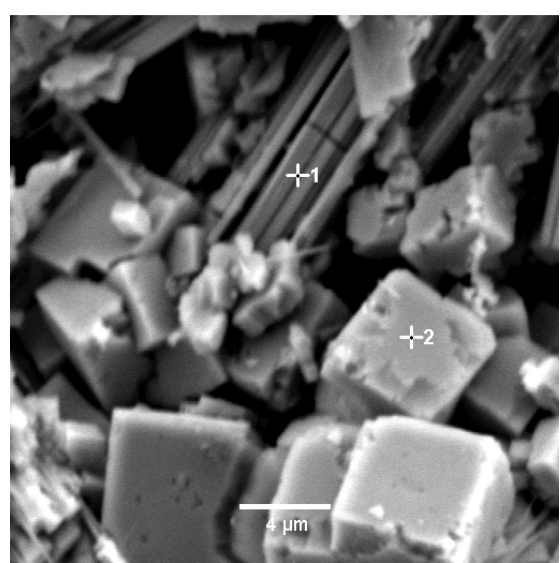

(e)

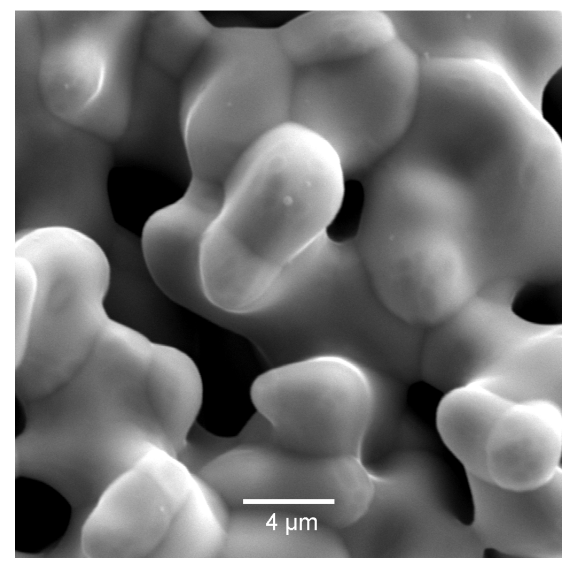

Fig. 4. Scanning electron microscopic images of material occurring at different stages during an electro-deoxidation experiment of $\mathrm{TiO}_{2}$ under the conditions specified in Fig. 3; (a) $\mathrm{TiO}_{2}$; (b) $\mathrm{Ti}_{2} \mathrm{O}_{3} / \mathrm{CaTiO}_{3}$; (c) $\mathrm{CaTi}_{2} \mathrm{O}_{4}$; (d) $\mathrm{CaTi}_{2} \mathrm{O}_{4} / \mathrm{TiO}$; (e) $\mathrm{Ti}[\mathrm{O}]_{\delta}$. (Crosses indicate positions were elemental composition was measured.)

The above reactions are quoted with their standard electrode potentials $E^{0}$. These refer to unit activities at $900^{\circ} \mathrm{C}$ and the $\mathrm{Ca} / \mathrm{Ca}^{2+}$ standard, with pure liquid $\mathrm{CaO}$ as the reference state for the oxide, and have been calculated from known thermodynamic data. It is evident that the reactions become thermodynamically less favourable as the reduction proceeds but all of them require potentials less cathodic than that for $\mathrm{Ca}$ deposition. A few points are worthwhile noting. The reaction in Eq. 7 has no electrode potential as it is of a purely chemical nature. The standard electrode potential of the reaction in Eq. 8 cannot be calculated precisely as the Gibbs free energy of formation of $\mathrm{CaTi}_{2} \mathrm{O}_{4}$ is unknown, so only a limiting value may be given based on the fact that 
$\mathrm{CaTi}_{2} \mathrm{O}_{4}$ is more stable than the individual compounds $\mathrm{CaTiO}_{3}$ and $\mathrm{TiO}$. Finally, when calculating electrode potentials under non-standard conditions, the concentration and the activity coefficient of the $\mathrm{CaO}$ need to be taken into account. The latter is 0.029 at the given temperature and for the given reference state. The quantitative change of the electrode potentials for different $\mathrm{CaO}$ contents may be considerable, but the general tendencies outlined remain valid.

As mentioned above, the microstructure of the cathode changes dramatically during the reduction of $\mathrm{TiO}_{2}$ to Ti. Figs. $4 \mathrm{a}$ to $4 \mathrm{e}$ visualise the microstructural evolution. It is seen that the microstructures of the $\mathrm{TiO}_{2}$ feed material and the Ti-suboxide/CaTiO 3 mixtures are rather fine and dominated by interconnected spherical particles. The microstructure is then completely reconstructed twice. When the $\mathrm{CaTi}_{2} \mathrm{O}_{4}$ is formed, the microstructure becomes coarse and needlelike; and when the $\mathrm{CaTi}_{2} \mathrm{O}_{4}$ is broken down, the microstructure becomes fine again and is dominated by cuboid $\mathrm{TiO}$ particles. These then spheroidise to form the Ti product. The involvement of the $\mathrm{CaTi}_{2} \mathrm{O}_{4}$ in the reaction sequence is a critical feature of the reduction process. Firstly, the friability of the $\mathrm{CaTi}_{2} \mathrm{O}_{4}$ temporarily renders the cathode mechanically weak. Secondly, the breakdown of the $\mathrm{CaTi}_{2} \mathrm{O}_{4}$ bears the risk of the particles being formed becoming detached from the cathode. The Ti particles in the final product are globular with diameters of several micrometres and lightly sintered together, giving the typical sponge-type appearance. Obviously, the particles in the Ti product are much larger than those in the $\mathrm{TiO}_{2}$ feed material, but in view of the intermittent changes, this must not be interpreted as plain particle coarsening.

The anode reaction in the FFC-Cambridge process is the discharge of oxide ions of the melt at a carbon based anode and the release of carbon oxides. The generation of $\mathrm{CO}_{2}$ gas is preferred over $\mathrm{CO}$ gas due to the more efficient use of the consumable carbon anode and toxicity aspects. The generation of $\mathrm{Cl}_{2}$ is undesired. Possible anode reactions and the corresponding standard electrode potentials are as follows:

$$
\begin{array}{ll}
\mathrm{CO}+2 \mathrm{e}^{-}=\mathrm{C}+\mathrm{O}^{2-}, & E^{0}=+1287 \mathrm{mV} \\
\frac{1}{2} \mathrm{CO}_{2}+2 \mathrm{e}^{-}=\frac{1}{2} \mathrm{C}+\mathrm{O}^{2-}, & E^{0}=+1378 \mathrm{mV} \\
\mathrm{Cl}_{2}+2 \mathrm{e}^{-}=2 \mathrm{Cl}^{-}, & E^{0}=+3231 \mathrm{mV} .
\end{array}
$$

It is seen that $\mathrm{CO}$ and $\mathrm{CO}_{2}$ formation are thermodynamically favoured over $\mathrm{Cl}_{2}$ formation. However, it should be recognised that $\mathrm{Cl}_{2}$ formation is possible at potentials below the thermodynamic decomposition potential of $\mathrm{CaCl}_{2}$ of $3.2 \mathrm{~V}$ at $900^{\circ} \mathrm{C}$. This is a consequence of the reactive nature of the cathode, and becomes obvious when combining the electrode potentials for Eqs. 3 through 6 with that for Eq. 12. In the experiments it was indeed observed that a quantity of $\mathrm{Cl}_{2}$ was liberated during the current peak. It needs to be considered further that the anodic release of carbon oxides is associated with significant polarisation losses on the order of $1 \mathrm{~V}$, as determined in a separate study [9], whereas this is not the case for $\mathrm{Cl}_{2}$.

Unfortunately, current efficiencies in the experiments yielding Ti metal were only between 10 $20 \%$. This was attributed to the rather extended polarisation times at high applied potentials. As Ca is soluble in $\mathrm{CaCl}_{2}$, potentials somewhat below the decomposition potential of the electrolyte will give rise to the formation of a small amount of dissolved $\mathrm{Ca}$ in the electrolyte, and this imparts a degree of electronic conduction on the electrolyte that lowers current efficiency. In fact, the presence of dissolved $\mathrm{Ca}$ in the electrolyte is an undesired side effect, and not a requirement for reduction to go to completion. 


\section{Electro-deoxidation experiments with a three-terminal cell, ramped potential, and intermediate $\mathrm{CaO}$ concentration}

The set of experiments summarised in the foregoing section provided fundamental insights into the reaction pathway of the reduction of $\mathrm{TiO}_{2}$ to $\mathrm{Ti}$. However, that study also revealed several deficiencies like the slow rate of reduction, the low current efficiency, and the possible generation of chlorine at the anode. These issues prompted a second in-depth study on $\mathrm{TiO}_{2}$ reduction [10]. In this, a number of fundamental changes were made. Firstly, the $\mathrm{CaO}$ concentration in the $\mathrm{CaCl}_{2} \mathrm{was}$ increased to $2.0 \mathrm{~mol} \%$ so as to enable higher transfer rates of oxide ions across the electrolyte. Secondly, a pseudo-reference electrode was incorporated into the cell in order to permit better control over the cathodic reactions and, in particular, to avoid unnecessary calcium deposition at the cathode. Through the combination of cathodic potential control and enhanced overall reaction rate it was furthermore endeavoured to improve current efficiency. Thirdly, a potential ramp was introduced at the beginning of the polarisation regime so as to eliminate large initial current peaks. This, in combination with the increased $\mathrm{CaO}$ concentration, should suppress chlorine formation.

The experiments were performed by cathodically polarising $\mathrm{TiO}_{2}$ discs, of $2 \mathrm{~g}$ in mass and with $25-30 \%$ open porosity, and, as before, using a graphite anode, $900^{\circ} \mathrm{C}$ and argon atmosphere. However, potentials were now applied versus a pseudo-reference electrode of graphite. The appropriateness of such a surprisingly simple type of reference electrode had been validated before in a separate study [9]. Polarisation was commenced with a potential ramp of $300 \mathrm{mV} / \mathrm{h}$, target potentials were between -0.8 and $-1.6 \mathrm{~V}$ versus graphite and kept constant throughout the remainder of the experiment, and the overall duration was $16 \mathrm{~h}$ in each case. The samples prepared were then examined as before.

Fig. 5 shows a current versus time curve recorded during a reduction experiment of the above type. First the current increases with time and goes through two waves, then the current peaks, and finally it stabilises at a relatively high level. Overall, curves like the one on Fig. 5 have few salient features and are therefore of little analytical value.

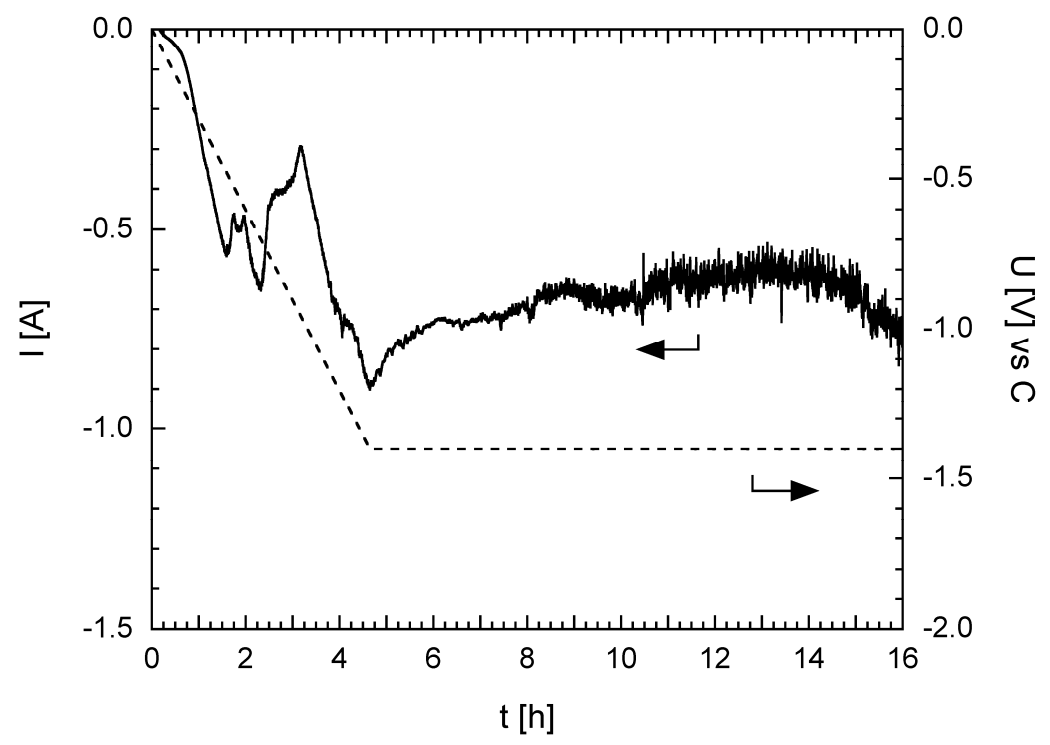

Fig. 5. Current versus time curve recorded during an electro-deoxidation experiment of $\mathrm{TiO}_{2}$ in a three-terminal cell; electrolyte: $\mathrm{CaCl}_{2}$ with 2 mol\% $\mathrm{CaO}$; cathode: porous $\mathrm{TiO}_{2}$ disc of mass $2 \mathrm{~g}$; anode: graphite; reference: graphite; applied potential versus reference: $300 \mathrm{mV} / \mathrm{h}$ to $-1.4 \mathrm{~V}$; temperature: $900^{\circ} \mathrm{C}$; atmosphere: dried argon. 
The reaction pathway was analysed primarily on the basis of phase composition, microstructure and elemental composition of the processed sample. On the whole, the conversion process was found to follow the same sequence of reaction, Eqs. 3 through 9, that was derived in the first study. The key finding in the second study was that the enhanced $\mathrm{CaO}$ concentration in the molten salt electrolyte led to a substantial increase of reaction rate, pointing to enhanced oxide ion transfer across the electrolyte. In addition, a number of new observations were made. While in the previous case oxygen removal only commenced after almost the entire cathode had been transformed into $\mathrm{CaTi}_{2} \mathrm{O}_{4}$, now the direct conversion of $\mathrm{Ti}_{2} \mathrm{O}_{3}$ and $\mathrm{CaTiO}_{3}$ to $\mathrm{TiO}$ at the edges of the sample was seen:

$$
\begin{array}{ll}
\mathrm{Ti}_{2} \mathrm{O}_{3}+2 \mathrm{e}^{-}=2 \mathrm{TiO}+\mathrm{O}^{2-}, & E^{0}=+664 \mathrm{mV}, \\
\mathrm{CaTiO}_{3}+2 \mathrm{e}^{-}=\mathrm{TiO}+\mathrm{Ca}^{2+}+2 \mathrm{O}^{2-}, & E^{0}=+139 \mathrm{mV} .
\end{array}
$$

The earlier onset of oxygen removal has also been attributed to the improved oxide ion transport in the electrolyte. Despite the general acceleration of the reduction process, and especially the faster breakdown of the $\mathrm{Ti}_{2} \mathrm{O}_{3}$ and $\mathrm{CaTiO}_{3}$, copious amounts of $\mathrm{CaTi}_{2} \mathrm{O}_{4}$ were still found in the core region of the samples. It was suggested that the formation of the $\mathrm{CaTi}_{2} \mathrm{O}_{4}$ from $\mathrm{TiO}$ and $\mathrm{CaTiO}_{3}$ is catalysed by the $\mathrm{CaO}$ dissolved in the $\mathrm{CaCl}_{2}$, suggesting that the intermediate presence of $\mathrm{CaTi}_{2} \mathrm{O}_{4}$ cannot easily be circumvented.

In addition to the general acceleration of the $\mathrm{TiO}_{2}$ to $\mathrm{Ti}$ conversion in the second study, some additional improvements were identified. The utilisation of a reference electrode has provided improved process control. More specifically, the demonstration of Ti formation at potentials less cathodic than that of $\mathrm{Ca}$ deposition has provided further evidence for the general concept of the process. The combined use of a reference electrode and an increased $\mathrm{CaO}$ concentration in the electrolyte have furthermore enabled attaining improved current efficiencies of up to $40 \%$. The combination of applying an initial ramp in the polarisation regime and increasing the $\mathrm{CaO}$ concentration in the electrolyte have rendered the reduction process essentially chlorine-free. Overall, the above conclusions demonstrate clearly that the $\mathrm{CaO}$ content of the electrolyte is a key parameter in the FFC-Cambridge process. Further to this, in the particular case of using a graphite based reference electrode, the $\mathrm{CaO}$ has another important function in that it defines the pseudopotential of the reference electrode [9].

In summary, the in-depth studies into the direct electrochemical reduction of $\mathrm{TiO}_{2}$ to $\mathrm{Ti}$ via the FFC-Cambridge process have provided a very detailed picture of the underlying fundamentals. It has been possible to derive a robust set of process parameters that ensures fast and efficient metalto-oxide conversion and adequate process control in experiments performed at a laboratory scale. This demonstrates the huge potential of the method, and patent protection for a number of key findings has been sought [11].

\section{Experiments on the Electro-deoxidation of Titanium Dioxide at Pilot Plant Level}

Soon after the invention of the FFC-Cambridge process, British Titanium plc was founded as a Cambridge University spin-out company and granted a licence for the production of titanium and alloys containing more than 40 mass $\%$ titanium. Initial work on scaling up the process took place within the Department of Materials Science and Metallurgy of the University of Cambridge and at QinetiQ, taking production quantities from a few grams to around $1 \mathrm{~kg}$ of titanium dioxide per batch. The pilot plant in the University was designed in-house and consisted of an externally heated, circular stainless steel vessel, enclosing a steel crucible, a ring of carbon anode rods, and a central cathode holder that contained the oxide precursors in a perforated steel basket. The set-up is displayed on Fig. 6. The QinetiQ pilot plant was similar in design and throughput. British Titanium 
took over the use of the University reactor in 2002 and eventually moved it to their premises in Cambridge. At the same time, design work was carried out to produce a larger capacity reactor.

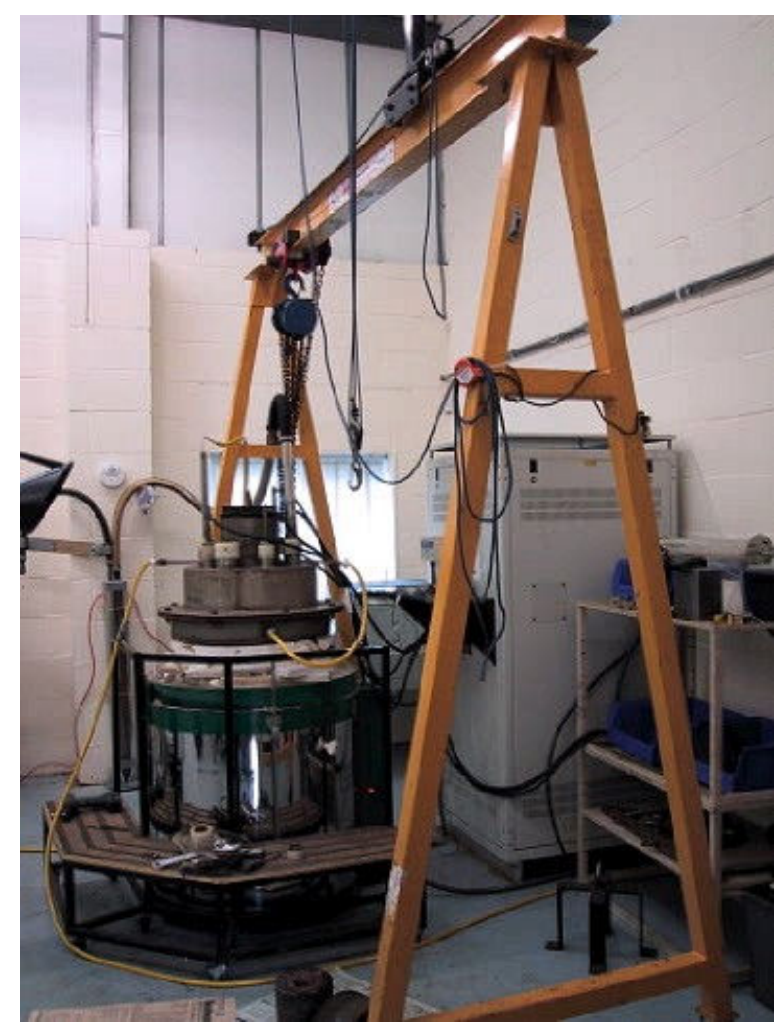

Fig. 6. Photograph of a pilot plant for electro-deoxidation experiments, showing steel vessel, furnace, power supply and lifting equipment.

The first experiments using the University reactor were prior to the elucidation of reaction pathways and the realisation of the importance of specific control of the electrolyte composition and cathode potential. Nevertheless, it was possible to produce kilogram quantities of titanium with relatively low oxygen contents in some batches, although the results remained inconsistent. When metal was produced, current efficiencies were typically a few percent only. At the same time, considerable plating of dendritic metal deposits was found on the outside of the cathode holder originating from the metal components of the reactor.

The above observations led to the testing of the University reactor with a porous refractory ceramic liner. This led to metal production at much higher current efficiency of around $15 \%$ and without the high levels of dendrite formation on the cathode holder. However, cooling of the reactor following the experiments led to the cracking of the outer steel shell due to thermal expansion mismatch between the salt and the steel, so this reactor was no longer functional.

The next reactor design was a planar cell with anode and cathode facing each other inside a square steel chamber and retro-fitted with a refractory liner. Above the chamber for molten salt was a second argon purged chamber into which the cathode could be retracted, removed from the reactor, and replaced. This enabled the reactor to remain at temperature and avoid the possibility of the shell cracking on cooling. Similarly, the anodes could be replaced as required without cooling the reactor. This reactor typically processed $2.5-3.5 \mathrm{~kg}$ of titanium dioxide per batch. Figs. $7 \mathrm{a}$ and $7 \mathrm{~b}$ show the custom-built cathode holder and the upper chamber. This design was conceived as being scaleable with multiple cathode-anode arrangements producing many tens or hundreds of kilograms of material per unit. 
(a)

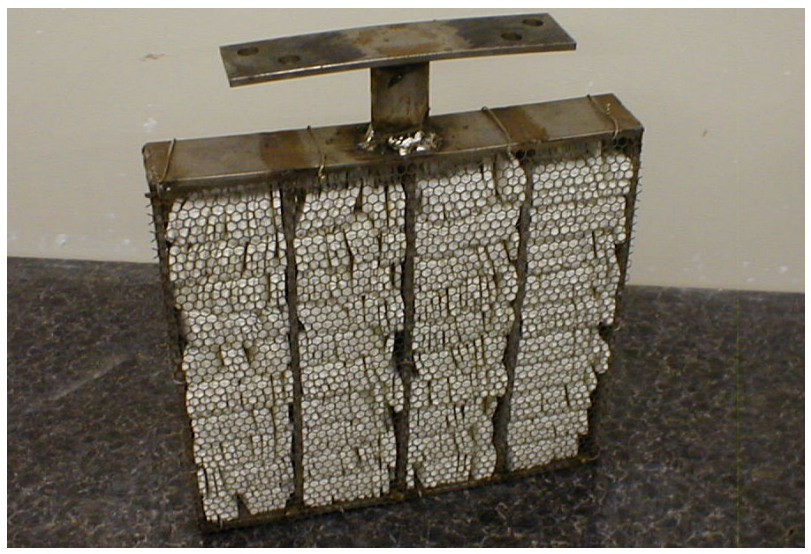

(b)

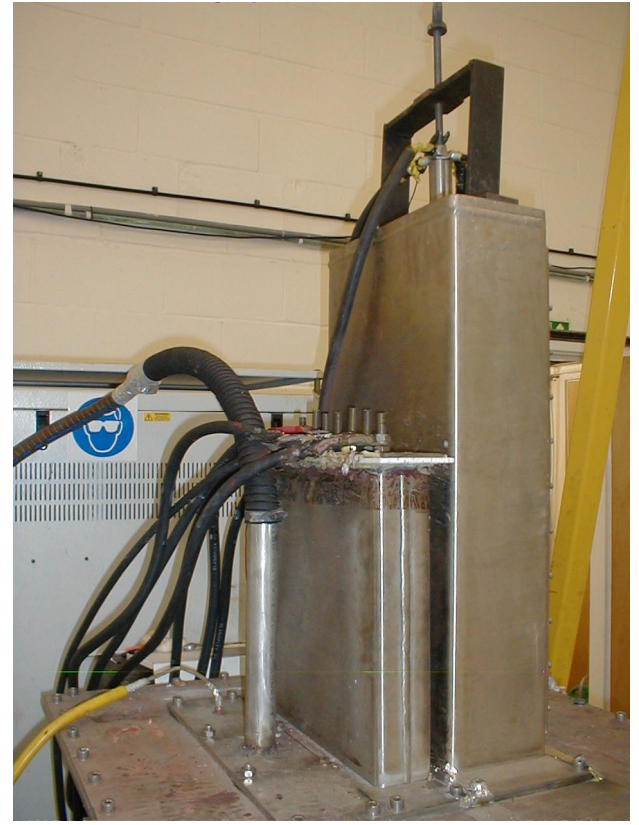

Fig. 7. Photographs of components of a pilot plant for electro-deoxidation experiments, showing (a) the planar cathode holder; (b) the upper chamber that enables exchange of electrodes in argon atmosphere while maintaining the reactor at temperature.

In all, eleven experiments were conducted with the above reactor at temperature for over six months. Many, although not all, batches produced fully metallised product, the best oxygen content measured being $800 \mathrm{ppm}$ by mass, with a current efficiency of approximately $28 \%$. Extensive optical microscopy was carried out on the products of these experiments and those carried out in other, smaller, reactors and much discussion took place with members of the University. These confirmed the reduction mechanisms being proposed and led to the measuring and adjusting of the electrolyte composition, as well as the incorporation of a pseudo-reference electrode in the planar cell to monitor and control the applied potentials. This explained the inconsistencies in product quality for those experiments carried out under imperfect conditions in the earlier work.

British Titanium together with members of Cambridge University, had discussions with Norsk Titanium AS with a view to collaborating in the further development of the FFC-Cambridge process via a joint venture. Norsk Titanium had connections with Hydro which has extensive experience of molten salt based processes and laboratory facilities suitable for relevant experimental work. It was decided to conduct a number of experiments jointly with members of Hydro in their laboratories in Porsgrunn. These made use of a more sophisticated monitoring and control system than that used at British Titanium, enabling remote adjustment of the operating parameters. The culmination of this work was the successful reduction of a batch of titanium dioxide in less than one day by interactively controlling the applied potential throughout the experiment. This was done by producing a suitable polarisation regime relative to a pseudo-reference electrode, and confirming the efficacy of the pseudo-reference electrode by comparison to a more sophisticated reference electrode made available by Hydro. Shortly after this, at the end of 2005, the British Titanium licence was terminated and unfortunately this fruitful collaboration came to an untimely end, although it was likely to pave the way towards commercialisation of the process.

Other groups have also worked on scaling up the FFC-Cambridge process, particularly QinetiQ, BHP Billiton and Metalysis, who are currently working together. It is not clear from their presentations that in the four years since the termination of the British Titanium licence, their efforts to scale up the process have progressed this technology further than had been achieved through the close collaboration between Cambridge University, British Titanium and Hydro. Work at British 
Titanium then focused on exploiting the FFC-Cambridge process for the production of oxygen from rocks by using inert anode technology, with a view to in-situ resource utilisation in extra-terrestrial areas. This programme was carried out in close collaboration with NASA.

\section{Recent Research and Development Activities}

Most of the work on the reduction of titanium dioxide via the FFC-Cambridge process was directed towards the production of titanium metal and titanium alloys in bulk quantities. In addition to this, several more specialised applications were envisaged. Two cases in point are the preparation of $\mathrm{Ti}$ coatings on steel through the reduction of deposited $\mathrm{TiO}_{2}$ [12], and the preparation of highly porous Ti metal through the reduction of $\mathrm{TiO}_{2}$ precursors containing fugitive additives [13]. These efforts were met with success and underscore the versatility of the process.

Arguably the biggest issues about operating the FFC-Cambridge process at a larger scale is the utilisation of a carbon based anode. Firstly, as carbon oxides are evolved and the anode is gradually consumed, particles of carbon can be eroded from the anode and build up as a sludge in the electrolyte, which can short-circuit the cell. Secondly, the $\mathrm{CO}_{2}$ may dissolve as the carbonate ion, $\mathrm{CO}_{3}{ }^{2-}$, in the electrolyte. The $\mathrm{CO}_{3}{ }^{2-}$ ions can diffuse to the cathode, where discharge and carbon deposition take place $[9,10]$.

$$
\mathrm{CO}_{3}^{2-}+4 \mathrm{e}^{-}=\mathrm{C}+3 \mathrm{O}^{2-} \text {. }
$$

The carbon deposit may contaminate the product although usually it can be wiped away readily. The main concern is that this parasitic reaction results in a reduction in the current efficiency.

A study was undertaken of the various materials that have been tried in the aluminium industry as inert anodes, and these included metals, cermets and tin oxide. Without exception all the metals and cermets tested very quickly eroded when an anodic potential was applied in a chloride based electrolyte. The only exception was tin oxide that lasted about $50-100 \mathrm{~h}$ before an insulating layer of calcium stannate formed on the anode and essentially terminated the experiment [14].

In some reductions of $\mathrm{TiO}_{2}$ it was noted that $\mathrm{CaTiO}_{3}$ deposited as a separate phase on the graphite anode surface in the course of the experiment [10]. As $\mathrm{CaTiO}_{3}$ is obviously stable in the chloride melt, it would make an ideal anode, except for the fact that it is a poor electrical conductor. It was first attempted to increase the defect concentration in $\mathrm{CaTiO}_{3}$ by doping with oxides that have a cation with a different valence to that of the host cation. However, only modest improvements of the electronic conductivity could be achieved. A search of the literature then showed that calcium ruthenate, $\mathrm{CaRuO}_{3}$, which is an excellent metallic conductor, forms a complete solid solution with $\mathrm{CaTiO}_{3}$. As might be expected, the conductivity decreases as the proportion of $\mathrm{CaRuO}_{3}$ in the solid solution decreases. At 10 mass $\% \mathrm{CaRuO}_{3}$, the conductivity has fallen by a factor of $10^{4}$ at room temperature. However, as the proportion of $\mathrm{CaRuO}_{3}$ decreases, the conductivity of the solid solution changes from that of a metallic conductor to that of a semiconductor. It is one of the properties of a semi-conductor that its conductivity increases with increase in temperature and it was found that at $800-900^{\circ} \mathrm{C}$, the solid solution's conductivity was around $10 \Omega^{-1} \mathrm{~cm}^{-1}$ which would be satisfactory for an electrode material [15].

Electrodes composed of the solid solution of $\mathrm{CaTiO}_{3}$ and $\mathrm{CaRuO}_{3}$ were fabricated and tested in oxide reduction experiments in molten $\mathrm{CaCl}_{2}$ based electrolytes. It was found that, provided there is about $1-2 \mathrm{~mol} \% \mathrm{CaO}$ in the melt, there was no erosion and the anodes were completely unaffected by the evolution of oxygen. The mass loss was $0.0015 \mathrm{~g} \mathrm{~cm}^{-2} \mathrm{~h}^{-1}$, which means that the anodes can be regarded as inert in these melts. It was also found that the $\mathrm{CaTiO}_{3} / \mathrm{CaRuO}_{3}$ anodes exhibit low polarisation losses for the oxygen evolution reaction. Therefore, the difference in anodic potential between $\mathrm{O}_{2}$ release on $\mathrm{CaTiO}_{3} / \mathrm{CaRuO}_{3}$ and $\mathrm{CO} / \mathrm{CO}_{2}$ release on graphite was significantly less than the $1 \mathrm{~V}$ indicated by the thermodynamics. Overall, by using the new material, the $\mathrm{CaCl}_{2}$ based melt remained white in appearance throughout the reduction experiments, and the current efficiency was 
increased by about $10 \%$ compared with the use of graphite anodes [15]. It should be noted that ruthenium is a relatively expensive metal which would preclude the use of pure $\mathrm{CaRuO}_{3}$, but a dilute solution of $\mathrm{CaRuO}_{3}$ in $\mathrm{CaTiO}_{3}$ with a 10 mass\% content of $\mathrm{CaRuO}_{3}$, corresponding to a 5 mass \% content of $\mathrm{Ru}$, is considered economically feasible. Again, patent protection is being sought [16], and large scale testing is envisaged in future work.

Overall, optimisation of processing conditions and utilisation of an inert anode has rendered possible the reduction of titanium dioxide to titanium metal via the FFC-Cambridge process within a timeframe of $14-16 \mathrm{~h}$, a current efficiency of around $40 \%$, and an energy consumption of around $17 \mathrm{kWh} \mathrm{kg}^{-1}$.

\section{Acknowledgements}

The authors gratefully acknowledge the generous financial support by EPSRC, EOARD, ONR, DARPA and NASA, as well as the co-operations with Norsk Titanium AS and Hydro.

\section{References}

[1] D.J. Fray, T.W. Farthing, Z. Chen: Patent WO9964638 (1999).

[2] G.Z. Chen, D.J. Fray, T.W. Farthing: Nature 407 (2000), 361.

[3] G.Z. Chen, D.J. Fray, in: Light Metals 2001, edited by J.L. Anjier, TMS (2001), p.1147.

[4] G.Z. Chen, D.J. Fray: J. Electrochem. Soc. 149 (2002), E455.

[5] D.J. Fray: JOM, 53 (2001), 26.

[6] D.J. Fray: Can. Metall. Q. 41 (2002), 433.

[7] C. Schwandt, D.J. Fray: Electrochim. Acta 51 (2005), 66.

[8] D.T.L. Alexander, C. Schwandt, D.J. Fray: Acta Mater. 54 (2006), 2933.

[9] C. Schwandt, D.J. Fray: Z. Naturforsch. A 62 (2007), 655.

[10] C. Schwandt, D.T.L. Alexander, D.J. Fray: Electrochim. Acta 54 (2009), 3819.

[11] D.J. Fray, C. Schwandt, G.R. Doughty: Patent WO2006027612 (2006).

[12] C. Schwandt, D.J. Fray: Ironmak. Steelmak. 34 (2007), 225.

[13] R.L. Centeno-Sánchez, D.J. Fray, G.Z. Chen: J. Mater. Sci. 42 (2007), 7494.

[14] K.T. Kilby, PhD Thesis, University of Cambridge (2008).

[15] S.Q. Jiao, D.J. Fray, Metall. Mater. Trans. B, in press.

[16] D.J. Fray, G.R. Doughty: Patent WO2009010737 (2009). 